\title{
Recycling New Energy - Discussion on the Application of Zero Waste to Taiwan Animal Husbandry
}

\author{
Chang-Hsien Hsu ${ }^{1}$ Chia-Chi $\operatorname{Lin}^{1} *$ \\ ${ }^{1}$ Department of Business Administration, Asia University, Taiwan
}

\begin{abstract}
With the rapid development of science and technology and the global warming caused by climate change, the extreme climate and the global plate have frequent effects, which not only seriously influence on the ecological environment, but also the shortage of natural energy caused by over-exploitation of human beings. Various countries have recognized nowadays the importance of energy and carbon dioxide emissions reduction, and with the development of circular economy issues, the governments realize that waste water discharged from high-value animal husbandry is a reusable resource. The environmental protection agencies cooperate with other agricultural institutions together in order to promote the policy of "returning fertilizer to the field". However, urine water will produce biogas during the treatment process. Its main component, methane $(\mathrm{CH} 4)$, is 25 times more than carbon dioxide (CO2), and the greenhouse effect caused by methane is carbon dioxide. But if the relevant technology is purified, methane becomes a good source of heat energy. If it is introduced into the generating set, it can become the daily electricity demand. For example, the principle of biogas power generation is to use the pig's excrement anaerobic and fermentation, then the gas generated in it is introduced into the generator to diversify energy utilization and make the effect of room gas reduction.In Taiwan, there is a unique geographical environment. The temperature is moderate and humid all year round which belongs to the maritime climate and makes all kinds of poultry grow well. The domestic stock farming output value accounts for about $30 \%$ of the total agricultural output value, and the pig industry value accounts for about $15 \%$ of the total agriculture, showing the importance of the pig industry in Taiwan. The government is responsible for taking care of the livelihood of the majority of pig farmers, taking into account environmental protection responsibilities, promoting agricultural and enterprise management, and raising green energy pigs. Marsh gas power generation is relatively stable compared to wind and solar power. It does not have to depend on the weather and it can also supply electricity during peak hours. For example, Denmark began the research 40 years ago. Marsh gas is not only the excrement of pigs, but also Cattle and sheep chicken manure, kitchen waste, animal carcasses, etc. In the process of bacteria decomposition of organic matter, it will release the main substances of biogas containing methane, carbon dioxide, hydrogen sulfide and other gases. In the light of this, the Industrial Technology Research Institute Branch in Taiwan has established the Office for Biogas Promotion Program in 2016. They actively promoted biogas promotion services, and gave relevant technology and knowledge to explore new energy opportunities and activate related industries. The international survey report pointed out that between 2050 and 2070 , the main energy sources for human beings will gradually dry up. Therefore, the application of recycling economy and resource reuse are much more important. This researchers invited " Universe Circular Technology" as the subject and we will discuss how enterprises respond to the government's promotion of circular economy policies, realize the new agricultural development that the government vigorously promotes, and use the regeneration of resources to solve the problem of energy shortage in Taiwan.
\end{abstract}

\section{Introduction}

In the 1970s, the global energy crisis and the increase of greenhouse gas emissions made countries pay more attention to the issues related to carbon reduction. In 2006, the UN Food and Agriculture Organization's report "Great Shadow of Animal Husbandry: Environmental Issues and Choices" stated that the greenhouse gas emissions generated by the industry account for $18 \%$ of the total global greenhouse gas emissions. In a report by the IPCC in 2018 , by the year 2052, the earth's temperature will exceed $1.5{ }^{\circ} \mathrm{C}$, which will cause irreversible damage to the earth. If no one take action, the heat wave caused by climate change, forest fires, natural disasters such as volcanic activity and rising sea levels will intensify, so it is imperative to achieve zero carbon emissions by 2050 . Since the 1973 energy crisis, governments around the world have positively sought new energy sources. In addition to solar, wind and ocean energy, biogas generated from the reuse of organic waste water in animal husbandry is an energy source with great development potential. The main components of Marsh

Corresponding author:becky123452001@gmail.com 
gas include methane (about $50 \%$ to $80 \%$ ), carbon dioxide (about $20 \%$ to $50 \%$ ), hydrogen sulfide, etc. Among them, methane is the main component of thermal energy. If the purity increases, the calorific value will be equal to with natural gas. It can quite replace natural gas and is not affected by the weather. The energy is safer and less polluting than fire and nuclear power.

From the above, we can find that the enthusiasm of government and private enterprises on environmental protection issues is the key to influence the global climate change. Government agencies not only actively promote the diversified utilization of renewable energy, but also need the cooperation and support with local enterprises in order to inject green energy into perseverance, showing the determination to save energy and reduce carbon emissions and greenhouse gas emissions. More than $90 \%$ of the energy in Taiwan must rely on overseas support. With the constraints of energy resources and international environmental protection, the development of low-carbon animal husbandry is one of the future trends.

In the view of the serious pollution of animal husbandry in Taiwan, Universe Circular Technology has introduced the most advanced biogas power generation technology and developed suitable technologies for power generation, biogas slurry and biogas residue treatment in Taiwan. For example, composting and biotransformation technologies are transformed into products such as power generation, feed and fertilizer, turning original waste into high value-added products, helping traditional agriculture and animal husbandry to move towards circular economy, and opening a new chapter for Taiwan's green energy.

\section{Zero waste and biogas power generation}

In the 20th century, due to environmental pollution, ocean acidification and climate warming caused by scientific and technological progress, the most urgent issues of concern in the world are how to save energy while reducing carbon emissions and create new energy for renewable energy. The group (OWG) emphasizes global climate change and calls for countries to cooperate to rapidly reduce global greenhouse gas emissions and to commit to global annual greenhouse gas emission reductions and emissions pathways by 2020 to allow global average temperature to increase below $2^{\circ} \mathrm{C}$ or $1.5^{\circ} \mathrm{C}$.

In the report "INTEGRATED BIOGAS SYSTEMS" published in May 2018, IEA pointed out that biogas produced by anaerobic digestion is a renewable energy product with multiple application functions, which can be used for heating, cooling and power generation. It can also be used as a fuel source for transportation vehicles. The main components of this gas are organic waste, such as agricultural and forestry livestock waste, industrial waste and specific crops produced by biogas. The biogas is produced through the recovery of the aforementioned waste. In addition to being used as an energy source, it can also reduce waste and emissions of greenhouse gases (such as methane gas) from waste processes.

Under the circumstance of depletion of natural resources and serious pollution of livestock waste, the "linear economy" model, which has developed a large amount of natural resources from the early stage, massproduced, thus generated a large amount of waste, has gradually transformed into a model of "cradle to cradle". A circular economy model that promotes the concept of zero waste and increased production value. The Environmental Protection Agency in Taiwan promotes green production with the direction of "source reduction and resource recovery", effectively recycling resources, gradually achieving the goal of full waste recycling and zero waste. Furthermore, referring to the buried biogas treatment model of advanced environmental protection countries in Europe and America, in these years, the government decided to cooperate with the private sector to build the biogas treatment power generation facility. It was officially put into operation on November 1, 1980. In addition to developing about 5 million watts of electricity, it will improve the air pollution in the landfill and convert the resources available in the biogas and develop new resources and implement the spirit of resource recycling.

\section{Implementation}

Biogas power generation is the most promising environmentally-friendly power generation method in Taiwan in recent years. Compared with wind and solar power generation, biogas sources are relatively stable. In addition to not to depend on the weather, it can also supply electricity during peak hours. The COA is cooperate with the policy of the Executive Yuan that in 2017, one million pigs will be used to generate electricity. In 2020, it will increase to 2.5 million pigs. That is, one out of every two pigs can generate electricity. According to the difference of fermentation systems, 2.5 million pigs are expected to produce 91.25 million of electricity in the whole year for about 2,500 homes throughout the year.

The most number of pig farms is in Pingtung County. The earlier smell of pig farms and the pollution of rivers often cause people to rebound. For this problem (Figure 1), Universe Circular Technology applies foreign biogas power generation technology for the manure and urine produced by pigs, and the biogas residue. In the process, those will be supplied to the screen by the technology of 
earthworms and microbes using anaerobic fermentation,composting and biotransformation technology. As a feed and fertilizer product of cultivated crops, Dafong Livestock Farm converts the original waste into high value-added products, breaks the pattern that was abandoned after the traditional use, and uses the waste water for agricultural irrigation. The harvest rate of crops is increased by $30 \%$, and the treated sewage is completely with the water standard without any odor, achieving the goal of real energy saving and carbon reduction and resource reuse.

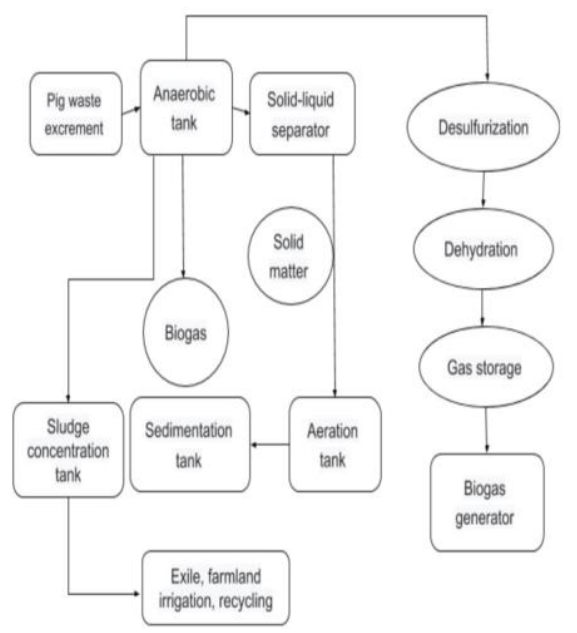

Figure 1. Flow chart of biogas reuse equipment

Nowadays, Taiwan faces problems such as insufficient power, industrial and commercial power grabs, and nuclear power plants to resume operations. In the policy of developing new energy, the actual implementation should not only avoid unintended damage to the natural ecology, but also implement zero-waste recycling and recycling economy. The concept of developing biomass energy, Universe Circular Technology transforms livestock waste into effective energy, breaking the traditional "disposal after use" model, and effectively utilizing agricultural waste to efficiently generate electricity in the process of wastewater purification for the problem of power shortage and pollution of agricultural sewage, and patent research and development to deal with the treatment of biogas slurry and biogas residue after power generation, and effectively reinvest it into the circular economy to create a favorable development environment for renewable energy in Taiwan.

\section{Conclusion}

Recently, the rise of environmental awareness and the climate change caused by global warming, all countries in the world have tried their best to respond to energy conservation and carbon reduction. In response to the trend of green environmental protection, business operations must cooperate with the government to promote sustainable business policies and transform into a green and zero-abandoned enterprise. However, the increase in carbon dioxide concentration caused by climate change, companied with the shortage of natural energy, have become the primary development and solution for the whole world. In addition, how to effectively apply the concept of zero-waste renewable resources to enterprises makes $\mathrm{CO} 2$ emissions reduced by effective resource recycling to reduce greenhouse gas emissions.

Taiwan is a medium-sized island located in the western subtropical zone where possesses the potential to develop renewable energy such as solar energy, biomass energy, wind power and geothermal energy. At present, renewable energy is not fully developed in Taiwan. The dependence rate of imported energy is as high as $97.82 \%$ in 2019 with the import traditional fossil fuels such as coal, oil, natural gas and uranium. The livestock industry accounts for a relatively high proportion of Taiwan's agricultural production and its gross domestic product exceeds 100 billion annually, accounting for more than $33 \%$ of the total agricultural product production. However, it will bring a lot of waste water during its development. Problems such as animal and animal odors, as well as the demand of the domestic people for the quality of the living environment, the problem of animal husbandry and odor has also risen, and the three major impacts on the environment with waste water and the waste.

Therefore, the animal husbandry industry must focus on the improvement of production efficiency and the end treatment of waste pollution, and with the implementation of the global carbon reduction campaign to develop the energy reduction, waste water conservation, recycling and other energy reuse. Thee zero waste will be the focus of the development of biogas power generation, and the Agriculture Committee will promote the concept of waste green gold energy for domestic animal husbandry, and cooperate with private enterprises with professional technology to help set up biogas power generation and other related facilities, improving livestock manure treatment equipment and plant, and transforming mud for organic composting, which not only promotes renewable energy, creates circular agriculture, but also hopes to solve industrial pollution problems through circular economy and develop green energy.

In order to realize non-nuclear countries, Taiwan must actively promote renewable energy development, set renewable energy development goals, and effectively reduce greenhouses through mutual cooperation between private enterprises and government agencies to promote people to understand more about the major environmental issues facing the world. 


\section{Reference}

1.Intergovernmental Panel on Climate Change. Climate Changes 2014 Report. Geneva:World Meteorological

Organization. 2014. pp. 2-5

2.Guo, M, D., \& Hsiao, T, S. (2009). Biogas utilization technology and examples. Council of Agriculture, Executive Yuan.

3.Wellinger, A., A, Lindeberg. 1990. Biogas upgrading and utilization. Task 24: energy from biological conversion oforganic wastes, pp.1-19

4.Glaub, J. C., Digz L. F. 1981. Biogas purification processes. Biogas and alcohol fuels production. Biocycle Journal of waste recycling Vol. II.

5.Ole Hjelmar,1996. WASTE MANAGEMENT IN DENMARK. Waste Management Vol.16Nos 5/6 pergamon PII:S0956-053X (96)00083-9pp389-394 